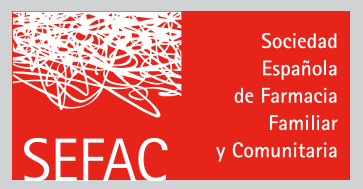

\title{
El papel del farmacéutico comunitario en la crisis de la COVID-19
}

\section{Luis Salar}

Director de FARMACÉUTICOS COMUNITARIOS.

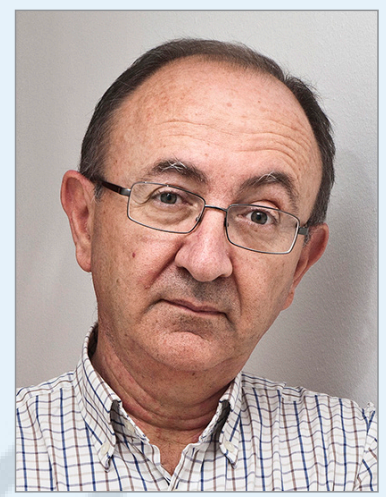

Luis Salar

\section{PALABRAS CLAVE}

Farmacia comunitaria, COVID-19

\section{KEYWORDS}

Community pharmacy, COVID-19

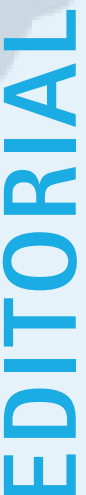

En diciembre de 2019 empezaron a aparecer en la ciudad de Wuhan (China) algunos enfermos por una neumonía distinta a la habitual. El último día del año, el Gobierno chino comunicó a la Organización Mundial de la Salud (OMS) la detección de un nuevo virus altamente contagioso.

China está muy lejos y, en enero, el entonces llamado por los medios "virus de Wuhan" salía poco en los telediarios. Sin embargo, el día 23 de ese mismo mes, las autoridades chinas decretaron el confinamiento en una ciudad de 11 millones de habitantes. Esta es una medida muy drástica y una señal de que el problema era realmente serio.

El 31 de enero, un mes después de que se diera el aviso de la presencia del nuevo virus, se detectó el primer caso en España y el 13 de febrero el primer fallecimiento, aunque este dato se conoció 20 días después de producirse. El 11 de marzo la OMS caracterizó a la COVID-19 como pandemia y el 14 de marzo se decretó el Estado de Alarma en España y el confinamiento general de la población.

En el marco del Estado de Alarma y de las restricciones de movilidad decretadas por el Gobierno, la farmacia comunitaria (FC) se considera un servicio esencial y debe seguir prestando asistencia a la población; algo que hace con la profesionalidad habitual. Los centros de salud han cerrado muchas de sus instalaciones durante la crisis o han pasado las consultas al modo telefónico, por lo que las FC han quedado en muchas ocasiones como el único establecimiento sanitario próximo a los pacientes y plenamente accesible. La población acude en masa a los supermercados a por papel higiénico y a las farmacias a por mascarillas. La comparación no es casual, ya que el 23 de marzo, Fernando Simón, director del Centro de Coordinación de Alertas y Emergencias Sanitarias del Ministerio de Sanidad, vino a decir en rueda de prensa, poco más o menos, que el riesgo de los farmacéuticos es el mismo que el de las cajeras de supermercados. Esto puede ser una frase dicha algo a la ligera como consecuencia de la presión a la que, indudablemente, ha estado sometido, pero indica bastante bien el concepto que en algunas instancias se tiene de la FC: poco más que un comercio. El caso es que el Ministerio de Trabajo, en su documento Prevención de riesgos laborales vs COVID-19, publicado en abril, excluyó también a las farmacias comunitarias del sector sanitario, vinculándolas con el comercial. Un hecho este que, afortunadamente, el Ministerio de Trabajo y Economía Social rectificó recientemente, entre otros motivos por la solicitud de SEFAC y a petición de grupos políticos en el Congreso de los Diputados.

A pesar de esta escasa sensibilidad e, incluso, desconocimiento por parte de la Administración, la FC ha seguido atendiendo a la población perfectamente. Afortunadamente no ha habido más desabastecimiento del habitual, salvo en los llamados "productos COVID": mascarillas, gel hidroalcohólico, guantes... Y los farmacéuticos comunitarios nos hemos dotado de los medios de seguridad como hemos podido (mamparas, señalética para la distancia de seguridad, mascarillas, etc.), unos más y otros menos. En esta situación el apoyo de los Colegios y la Distribución Farmacéutica ha sido importante. También hemos contado rápidamente con infinidad de protocolos publicados por sociedades científicas $\mathrm{y}$ corporaciones profesionales.

\section{¿Cómo se ha visto afectada la labor farmacéutica?}

En contra de todo esto, y a pesar de la buena disposición profesional de las farmacias y del resto del sistema sanitario, 
tenemos que admitir que no estábamos preparados para epidemias de este tipo. Nadie lo estaba. El trabajo se ha complicado. Es difícil prever algo que ninguno de nosotros ha vivido anteriormente, y nuestros padres tampoco. $\mathrm{Y}$ hay otro detalle, ¿estamos vacunados? Es obvio que contra la COVID-19 no lo estamos, pero ¿y la gripe? En algunos estudios se demuestra que la cobertura vacunal entre los sanitarios, incluyendo a los farmacéuticos, es muy baja. Cuando la vacuna de la COVID-19 esté disponible deberemos vacunarnos todos.

La atención a la población ha variado sobre la habitual antes de la pandemia. El número de consultas que se reciben sobre temas relacionados con la COVID-19 es enorme. La FC es una fuente de información sanitaria veraz y creíble y, por este motivo, se ha hecho también una labor importante desmintiendo los muchos bulos que han circulado desde el inicio de la pandemia.

Algunos pacientes con síntomas también han acudido, y siguen haciéndolo, a la farmacia a consultar y se han desarrollado protocolos para atenderlos con seguridad. La atención a otros pacientes con consultas de Indicación Farmacéutica ha tenido que ser distinta, pues había que derivar al médico lo menos posible, por las condiciones limitadas de atención en algunos centros de salud.

Otra labor que hemos desarrollado, no menos importante que lo ya dicho, ha sido la de tranquilizar a la población. Se ha trabajado para disminuir su nivel de estrés e insistir hasta la saciedad en las medidas de seguridad más importantes, como la distancia de seguridad, el lavado frecuente de manos y la limpieza de superficies. Y, sobre todo, permanecer en casa.

\section{Actividades farmacéuticas durante la crisis}

En general, durante la crisis, la sensación general de los farmacéuticos comunitarios, según diferentes encuestas, es de abandono por parte de la Administración. Pero, parafraseando a Kennedy, no nos preguntemos qué puede hacer nuestro país por la farmacia; mejor preguntémonos qué puede hacer la farmacia por nuestro país y por los pacientes a los que atendemos todos los días. Aquí hay muchas opciones entre las que el reparto de mascarillas, que ha protagonizado muchos titulares es, probablemente, la menos importante.

La dispensación con entrega en el domicilio del paciente es otra de las labores que han aflorado en esta crisis. Se ha querido regular la "dispensación" a domicilio, pero lo que realmente se ha regulado es la "entrega". Las distintas autoridades tardaron en hacerlo, pero es obvio que en algunos casos se ha tenido que hacer, con pacientes ancianos habituales, por cuestiones humanitarias de urgencia y necesidad. No olvidemos que la denegación de auxilio es un delito.
No obstante, sería mucho mejor regular la atención farmacéutica domiciliaria (AFD). Cuando el confinamiento acabe seguirá habiendo algunas personas mayores con problemas para desplazarse hasta la farmacia. SEFAC ya presentó una propuesta sobre AFD en su congreso de 2018 en Alicante y recientemente ha publicado también una propuesta para la dispensación de medicamentos y productos sanitarios, que incluye también la indicación farmacéutica con entrega en el domicilio del paciente durante el Estado de Alarma por COVID-19, así como una hoja de registro para documentar esta actividad.

También se ha hablado mucho en estas semanas de la dispensación de medicamentos hospitalarios en FC. En algunas comunidades autónomas se ha hecho y ha funcionado bien. En otras, sin embargo, se ha enviado el medicamento a domicilio por mensajero. Parece que un mensajero entrega el medicamento mejor que un farmacéutico comunitario, pero eso no significa que lo dispensa. ¿O es que el medicamento hospitalario no necesita ser dispensado por un farmacéutico?

Igual que se ha organizado la distribución de las mascarillas a través de las farmacias se podrían realizar los test rápidos de COVID-19 en nuestros establecimientos. En las farmacias tenemos la capacidad técnica suficiente para hacerlo, los pacientes se desplazarían menos, no irían a centros "presuntamente infectados" y el sobrecargado personal sanitario de los hospitales podría dedicarse a otras cosas. Podrían prescribirse en la receta electrónica y habilitarse una web para introducir el resultado. Desde SEFAC también se ha trabajado en un plan formativo al respecto y ofrecido a la Administración.

Además, y en el marco de nuestras competencias, los farmacéuticos comunitarios podemos vigilar, y acompañar, a los pacientes frágiles, que todos tenemos y conocemos, mediante llamadas telefónicas a su casa para asegurarnos de la efectividad y seguridad de sus medicamentos, tanto de los habituales como de los de la COVID-19 si están afectados. Y también asesorar en posibles problemas derivados del confinamiento: insomnio, ansiedad, trombosis venosa profunda por falta de ejercicio, y también hiperglucemias por la misma razón.

Quizá lo más importante de toda esta crisis es que, una vez más, y esperamos que ahora sí, sirvan para algo las lecciones recibidas, es imprescindible avanzar en la coordinación y comunicación entre profesionales y, en particular, entre los que ejercemos en las farmacias comunitarias y los centros de salud. Para ello, hace falta establecer una vía de comunicación bidireccional directa y efectiva. El teléfono no sirve, no debe servir, y ahora menos: siempre comunica. Médicos, enfermeros y farmacéuticos de una misma área debemos conocernos y colaborar. Es el paciente el que saldrá beneficiado. Ahora y en crisis venideras. 